\title{
PENGGUNAAN BENDUNG KONSOLIDASI SEBAGAI KONTROL MUKA AIR UNTUK MENGURANGI RESIKO LONGSOR PALUNG SUNGAI BRANTAS DI KAMPUS III UNIVERSITAS MUHAMMADIYAH MALANG
}

\section{USE OF CONSOLIDATION DAM AS A WATER FLOW CONTROL TO REDUCE THE RISK OF BRANTAS RIVER LANDSLIDE IN CAMPUS III MUHAMMADIYAH UNIVERSITY, MALANG}

\author{
Chairil shaleh ${ }^{1}$, Sulianto ${ }^{2}$, Ach Hadi $\mathrm{S}^{3}$ \\ Fakultas Teknik Jurusan Teknik Sipil Universitas Muhammadiyah Malang \\ Alamat : Jl. Raya Tlogomas, No. 246 Malang \\ Email : chairil@umm.ac.id
}

\begin{abstract}
Analysis of velocity in the river segment is a first step in determining step efforts to solve the problems that occur scour the riverbed. Along with the development of software so rapidly is often the choice of mathematical models as a tool to obtain the behavior occurs, because in addition to its low cost. This model can cover dimensions of space and long term. Surface Water Modeling System a program to solve a mathematical model that builds on the concept of movement of water and sediment movement are mathematically solved by using the finite element method through a horizontal two-dimensional approach. This model is expected to provide satisfactory results to improve the performance of methods common approach used previously.The research location is next Brantas River Campus III UMM Malang in East Java which have problems of scouring in the river. From the analysis shows scour flow rate level is very large, with Manning entering a value $n=0,045$, obtained the results of a very high speed is Maximum $=0.25 \mathrm{~m} / \mathrm{s}$ and Minimum $=0.03 \mathrm{~m} / \mathrm{s}$ exceeds the critical velocity for $D_{50}$ is 0.045 $\mathrm{m} / \mathrm{s}$, while the results obtained weir placement results for Maximum speed $=0043 \mathrm{~m} / \mathrm{s}$ and Minimum $=0.010 \mathrm{~m} / \mathrm{s}$ below the critical speed of the $D_{50}$.
\end{abstract}

Keywords: River; Weir; Scours; Steady.

\begin{abstract}
Abstrak
Analisa kecepatan aliran pada ruas sungai merupakan tahap awal dalam menentukan penanganan masalah gerusan yang terjadi pada palung sungai. Seiring dengan perkembangan piranti lunak (software) yang demikian pesat model matematika menjadi pilihan sebagai alat untuk memperoleh perilaku yang terjadi, karena disamping biayanya yang murah model ini dapat mencangkup dimensi ruang dan waktu. Surface Water Modeling System merupakan salah satu program untuk memecahkan model matematika yang dibangun berdasarkan konsep gerak air dan gerak sedimen yang secara matematis dipecahkan dengan menggunakan metode elemen hingga (finite element) melalui pendekatan dua dimensi horisontal. Dengan berbagai kelebihannya, model ini diharapkan mampu memberikan hasil yang memuaskan sehingga dapat memperbaiki kinerja dari metode-metode pendekatan yang umum digunakan sebelumnya. Lokasi penelitian di Sungai Brantas depan Kampus III UMM di Kabupaten Malang Jawa Timur yang memiliki masalah akibat gerusan di Palung Sungai. Dari hasil analisa terhadap gerusan yang terjadi memperlihatkan tingkat kecepatan aliran sangat besar, dengan memasukan nilai $\mathrm{n}$ Manning $=0,045$, di peroleh hasil kecepatan yang sangat tinggi yaitu Maksimum $=0.25 \mathrm{~m} /$ det dan Minimum $=0,03 \mathrm{~m} /$ det melebihi kecepatan kritis $\mathrm{D}_{50}$ sebesar $0,045 \mathrm{~m} / \mathrm{det}$, sedangkan hasil penempatan bendung didapat hasil kecepatan sebesar Maksimum $=0.043 \mathrm{~m} /$ det dan Minimum $=0,010 \mathrm{~m} /$ det dibawah kecepatan kritis $\mathrm{D}_{50}$.
\end{abstract}

Kata kunci : Sungai; Bendung; Gerusan; Steady;

\section{PENDAHULUAN}

Sungai adalah suatu saluran drainase yang terbentuk secara alamiah. Akan tetapi disamping fungsinya sebagai saluran drainase dengan adanya air yang mengalir di dalamnya, sungai menggerus tanah dasar nya secara terus-menerus sepanjang masa eksistensinya dan terbentuklah lembah lembah sungai. Volume sedimen yang sangat besar yang dihasilkan dari keruntuhan tebing 
sungai di daerah pegunungan dan tertimbun di dasar sungai tersebut terangkut kehilir oleh aliran sungai. Karena di daerah pegunungan kemiringan sungainya curam, gaya tarik aliran airnya cukup besar.

Tetapi setelah aliran sungai mencapai daratan, maka gaya tariknya sangat menurun. Dengan demikian beban yang terdapat dalam arus sungai berangsur angsur diendapkan. Karena itu ukuran butiran sedimen yang mengedap dibagian hulu sungai lebih besar daripada bagian hilirnya

Dalam hal ini peneliti menggunakan studi kasus yang terjadi pada ruas sungai Brantas di kampus III UMM, dikarenakan pada bagian hulu sungai sangat curam dan memiliki pola distribusi kecepatan aliran yang sangat tinggi pada kondisi existing, sehingga terjadi gerusan tanah yang mengakibatkan longsor, untuk itu perlu adanya identifikasi titik titik rawan longsor dan penentuan letak bendung yang mampu secara optimal menaikan elevasi muka air sehingga dapat mengurangi resiko terjadi longsor.

Berikut gambar terjadinya gerusan tanah pada ruas sungai Brantas kampus III UMM

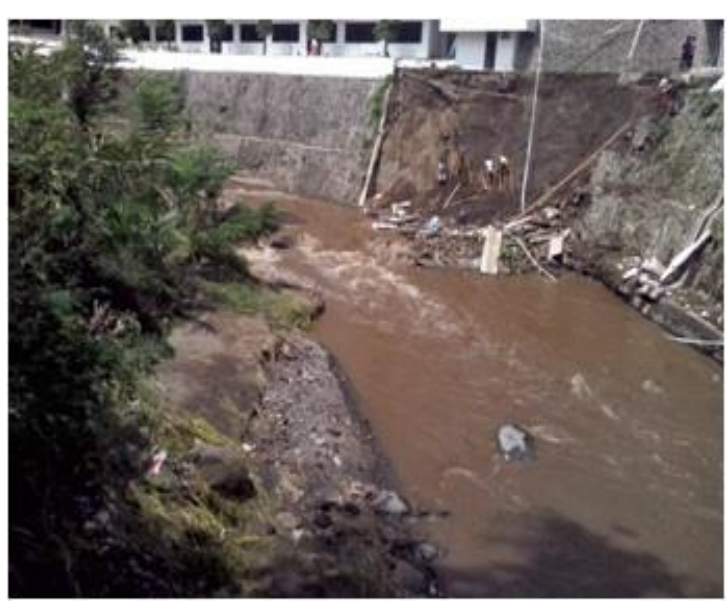

Gambar 1.a. Lokasi penelitian

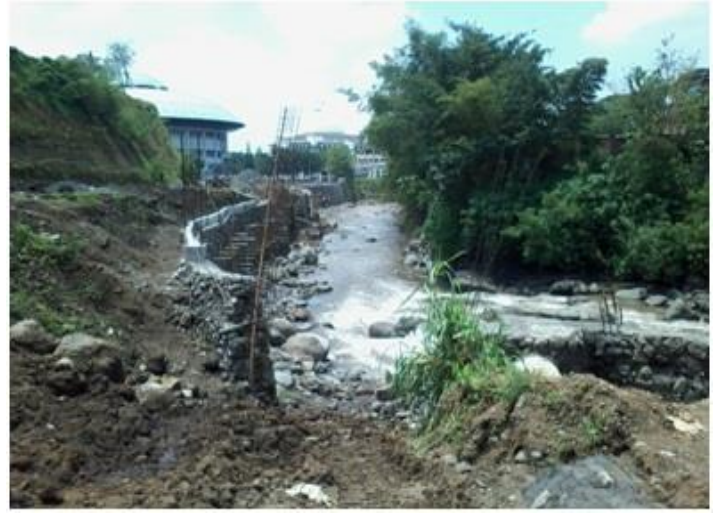

Gambar 1.b. Lokasi penelitian

\section{METODE PENELITIAN}

Lokasi studi adalah Sungai Brantas pada ruas sepanjang $500 \mathrm{~m}$ di area Kampus III UMM, lokasi tersebut terletak di Jln. Raya Tlogomas 246, Kabupaten Malang, Propinsi Jawa Timur. Secara topografi denah sungai ditunjukan pada gambar.1.

Semua data pendukung dalam kegiatan penelitian ini pada dasarnya berupa data primer dan sekunder yang bersumber dari hasil pengumpulan data lapangan dan Dinas Pengairan yang terkait adapun penjelasan mengenai data tersebut di jelaskan dibawah.

\section{Data Primer}

Data Primer meliputi :

- Geometri Sungai

Data geometri sungai di peroleh dari peta topografi sungai brantas dan dilakukan cross section,long section pada titik

- $\quad$ Sedimen Sungai

Data sedimen sungai di peroleh dari pengujian analisa saringan dengan mengunakan sampel sedimen yang diambil dilapangan secara langsung, pengujian ini bertujuan untuk memperoleh distribusi besaran atau jumlah persentase butiran baik agregat halus dan agregat kasar.

\section{Data Sekunder}

Data debit aliran di peroleh dari bendungan sengkaling dengan kala ulang 5 sampai 10 tahun terakhir. 


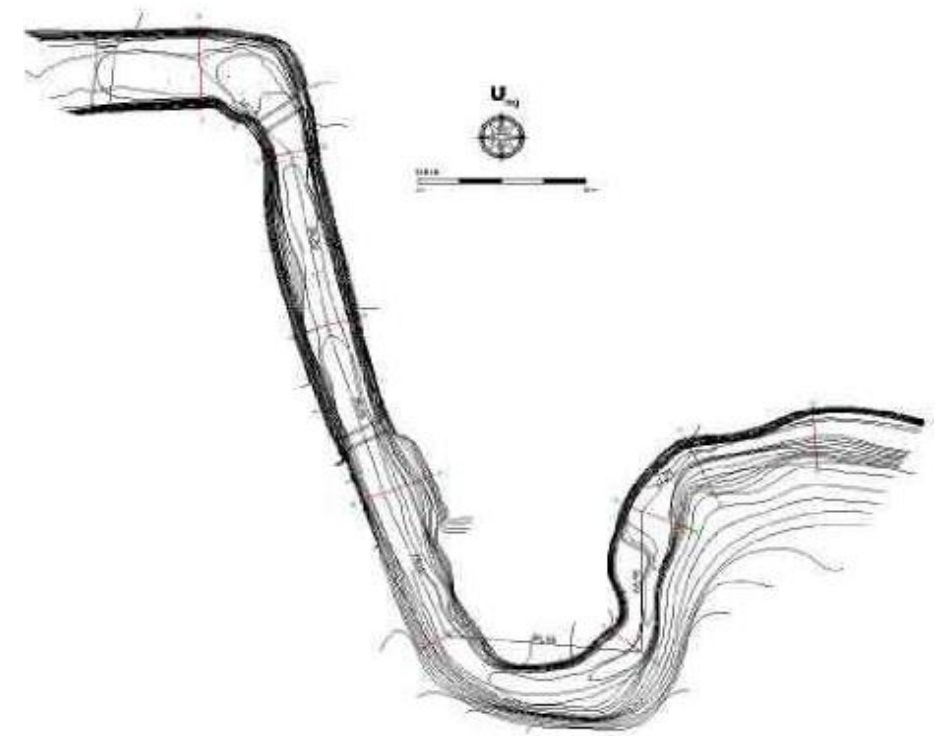

Gambar 2. Denah lokasi penelitian

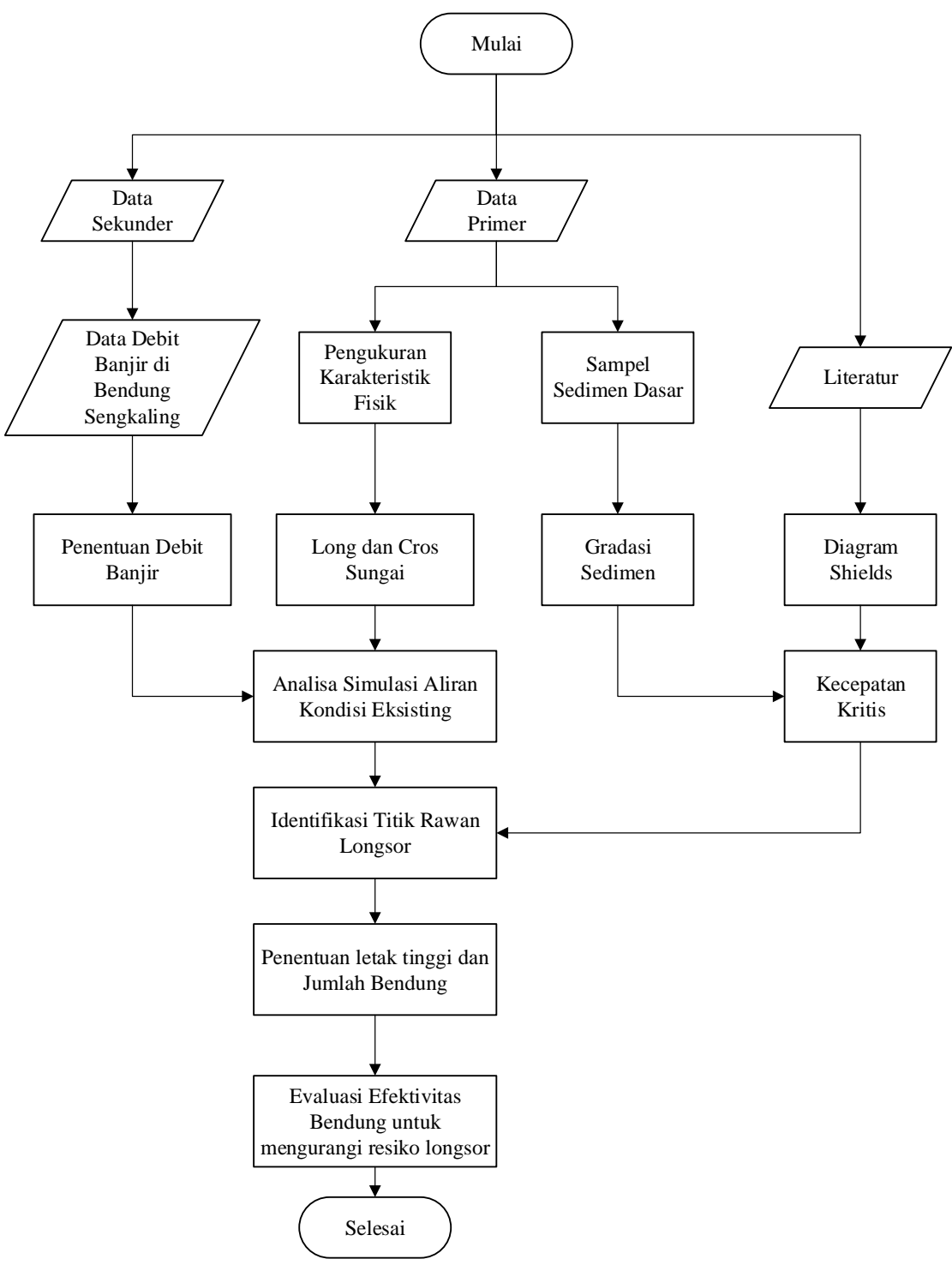

Gambar 3. diagram alir penelitian 


\section{HASIL DAN PEMBAHASAN}

\section{Geometri Sungai}

Potongan memanjang sungai long sections sepanjang $567.13 \mathrm{~m}$ dapat dilihat pada lampiran 1 dari hulu ke hilir. Detail potongan melintang dilihat pada Gambar berikut
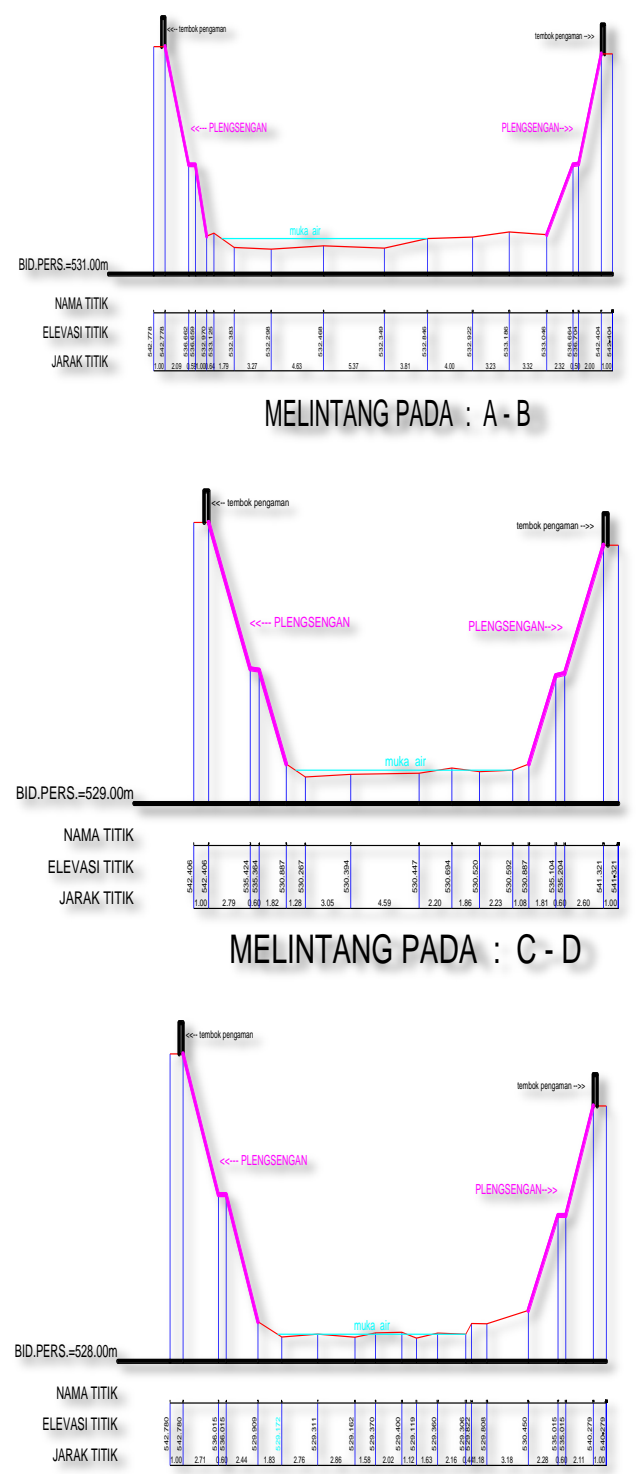

MELINTANG PADA : E-F

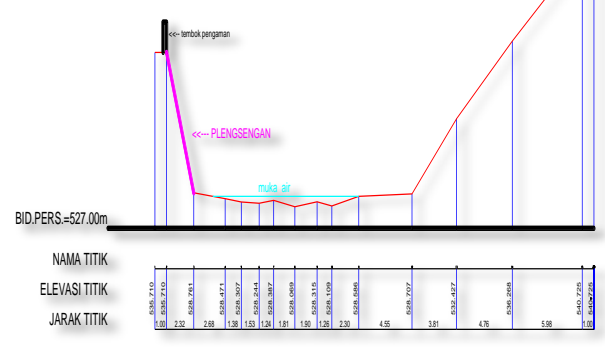

MELINTANG PADA : $G-H$

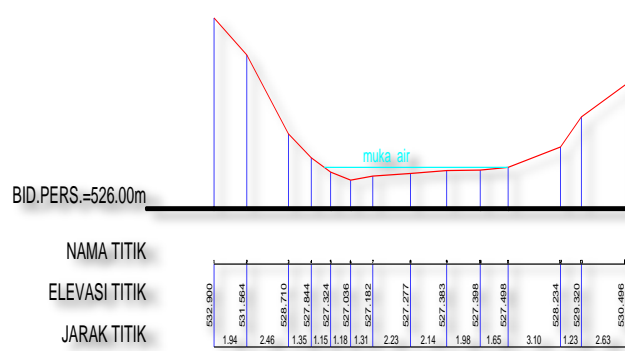

MELINTANG PADA : I- J

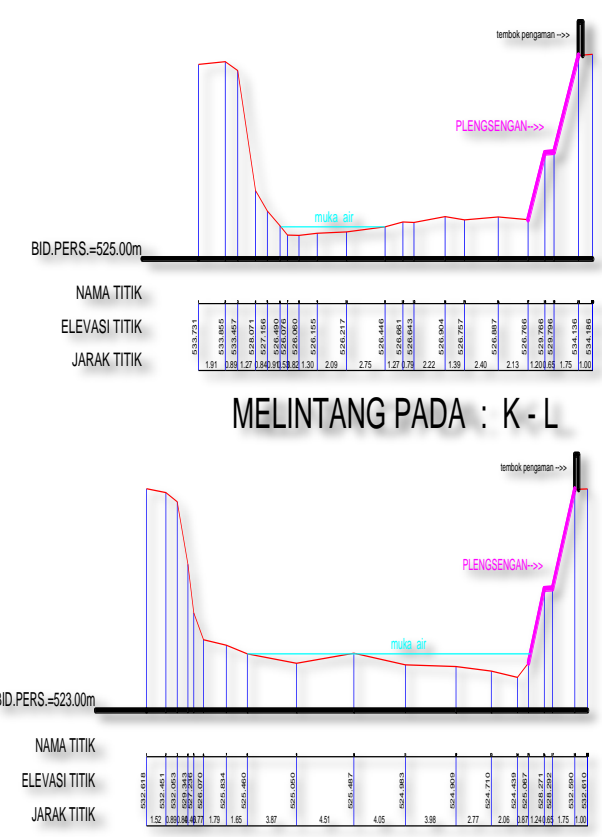

MELINTANG PADA : M - N

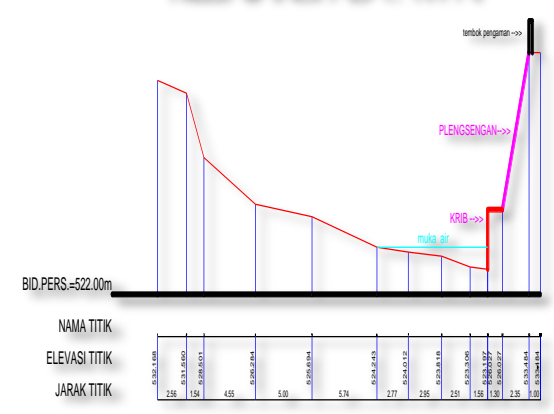

MELINTANG PADA : O-P

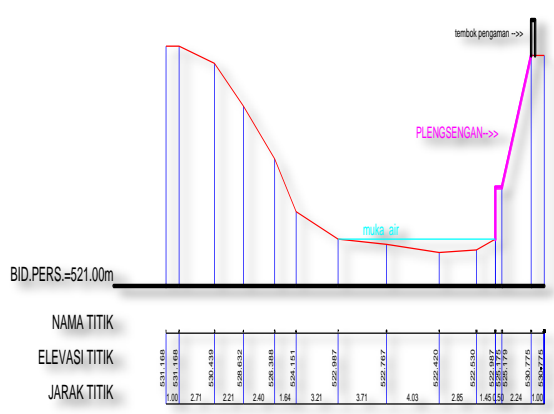

MELINTANG PADA : Q-R 
Tabel 1. Diameter Butiran Sedimen

\begin{tabular}{ccc}
\hline (Ø)Butiran & Tertahan (\%) & Lolos $(\%)$ \\
\hline d10 & 94.60 & 5.40 \\
d20 & 78.93 & 21.07 \\
d30 & 63.87 & 36.13 \\
d40 & 50.77 & 49.23 \\
d50 & 47.10 & 52.90 \\
d60 & 34.50 & 65.50 \\
d70 & 27.17 & 72.83 \\
d80 & 19.50 & 80.50 \\
d90 & 7.76 & 92.24 \\
d100 & 0.00 & 100.00 \\
\hline
\end{tabular}

\section{Karakteristik fisik sedimen}

Sedimen adalah pecahan-pecahan material umumnya terdiri atas uraian batubatuan secara fisis dan secara kimia. Partikel ini mempunyai ukuran dari yang besar (boulder) sampai yang sangathalus (koloid) dan beragam bentuk dari bulat, lonjong sampai persegi. (Triyanti Anasiru).

Dari penelitian yang berlokasi di Sungai Brantas Kampus III UMM, Data Sedimen Sungai diambil sebanyak $\pm 6 \mathrm{~kg}$ kemudian dilakukan pengujian di Laboratorium Mekanika Tanah dengan pemeriksaan ukuran butiran Sedimen, semua benda uji di Open selama 1 hari kemudian dilakukan Analisa Saringan dengan jumlah benda uji sebanyak 3000 gram, susunan ayakan yang di sediakan yaitu Fraksi Kasar $=($ 3inchi, 1 inchi, 3/4 inchidan $1 / 2$ inchi $)$, Fraksi Sedang $=(3 / 8$ inchi, No.4 dan No.8 ), Fraksi Halus = ( No.10, No.20, No.40, No.80, No.100, No.200) dari hasil Fraksi terlampir.

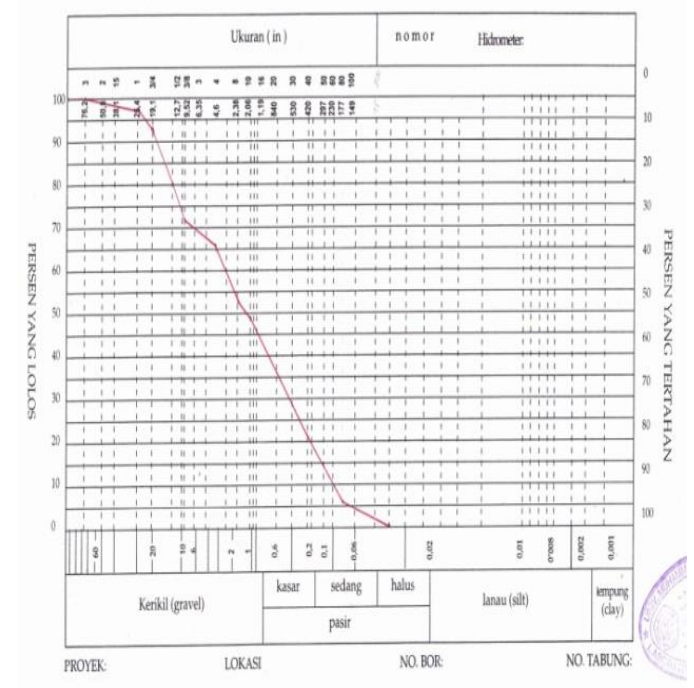

Dari grafik pembagian butiran sedimen di atas dapat disimpulkan bahwa sedimen sungai Brantas UMM kampus III, merupakan jenis krikil dan pasir. Ukuran butiran sedimen diperlukan untuk analisa transportasi sedimen berkenaan dengan kecepatan kritis. Kecepatan kritisa dalah kecepatan yang menyebabkan suatu butiran dengan diameter tertentu mulai bergerak. Untuk dapat menentukan setiap butiran bergerak terhadap kecepatan kritisnya pembagian butiran dari grafik diatas ditentukan nilai $\mathrm{D}_{50} . \mathrm{D}_{50}$ artinya diameter butiran rata-rata partikel yang 50\% lolos pada analisa saringan. Dari grafik di atas didapat $D_{50}=2,16 \mathrm{~mm}$. Selanjutnya berdasarkan $\mathrm{D}_{50}$ dan Utarakan diproses dengan Diagram Shields seperti pada gambar diatas

Tabel 2. diameter dan butiran kritis

\begin{tabular}{clc}
\hline $\begin{array}{l}\text { Diameter } \\
\text { Butiran }\end{array}$ & $\begin{array}{l}\text { ukuran } \\
(\mathrm{mm})\end{array}$ & V kritis m/det \\
\hline $\mathrm{d} 10$ & 0.23 & 0.013 \\
$\mathrm{~d} 20$ & 0.40 & 0.016 \\
$\mathrm{~d} 30$ & 0.55 & 0.016 \\
$\mathrm{~d} 40$ & 0.95 & 0.021 \\
$\mathrm{~d} 50$ & 2.16 & 0.045 \\
$\mathrm{~d} 60$ & 3.30 & 0.050 \\
$\mathrm{~d} 70$ & 6.38 & 0.080 \\
$\mathrm{~d} 80$ & 12.70 & 0.200 \\
$\mathrm{~d} 90$ & 18.10 & 0.600 \\
\hline
\end{tabular}

Tabel 3. Hubungan $\operatorname{Tr}$ dan debit rencana

\begin{tabular}{cc}
\hline Tr (tahun) & Q m3/det \\
\hline 50.00 & 271.25 \\
25.00 & 236.77 \\
10.00 & 190.59 \\
8.00 & 208.74 \\
4.00 & 146.51 \\
2.67 & 132.64 \\
2.00 & 88.70 \\
1.60 & 78.66 \\
1.33 & 78.66 \\
1.14 & 42.82 \\
\hline
\end{tabular}

Gambar 4. Grafik Pembagian Butiran. 


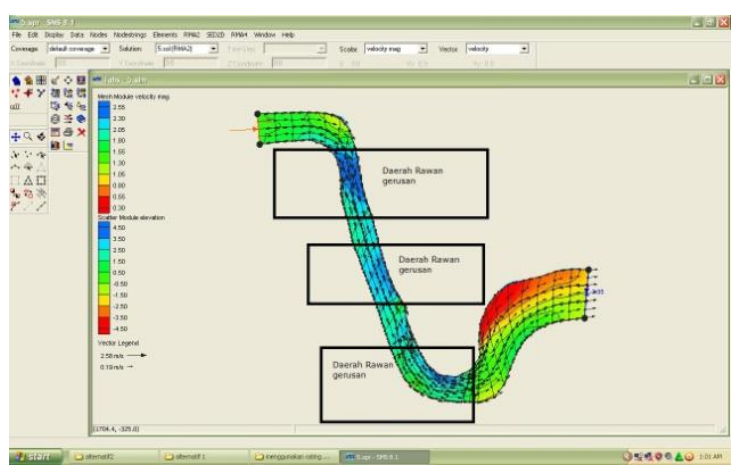

Gambar 5. profil aliran sungai pada kondisi eksisting.

Gambar diatas menunjukan bahwa nilai kecepatan yang terjadi adalah sangat besar yaitu minimum $0,03 \mathrm{~m} / \mathrm{det}$ dan maksimum sebesar $0.025 \mathrm{~m} / \mathrm{det}$, sehingga akan terjadi gerusan tanah di palung sungai mengingat nilai tersebut lebih besar dari nilai kecepatan kritis $\mathrm{D}_{50}$ sebesar $0,045 \mathrm{~m} / \mathrm{det}$.

Tabel.4. Ringkasan nilai kecepatan aliran kondisi eksisting

$$
\begin{array}{ll}
\text { n.Maning } & =0,045 \\
\text { Qt10 tahun } & =190,594 \mathrm{~m}^{3} / \text { det. } \\
\text { Kontrol Hilir } & =3.35 \mathrm{~m}
\end{array}
$$

\section{Hasil Analisis :}

\begin{tabular}{lll}
\hline \multicolumn{1}{c}{ Parameter } & $\mathrm{Vx}(\mathrm{m} /$ detik) & Vy (m/detik) \\
\hline $\begin{array}{l}\text { Statistik } \\
\begin{array}{l}\text { Maksimum } \\
\text { (m/det) }\end{array}\end{array}$ & $\mathrm{E}=20000$ & $\mathrm{E}=20000$ \\
$\begin{array}{l}\text { Minimum } \\
\text { (m/det) }\end{array}$ & 0.25 \\
Sumber : Hasil Analisa dengan program SMS 8.0.
\end{tabular}

\section{Kondisi Setelah Pemasangan Bendung}

1) Bendung di letakkan pada bagian ujung hilir sungai setinggi $3 \mathrm{~m}$

2) Data yang di masukan dalam simulasi ini:

- Kontrol hulu menggunankan debit QT $=190,594$

- Kontrol hilir menggunakan tinggi bendung $=3 \mathrm{~m}$

Menentukan daerah yang akan di ditempatkan bendung untuk mengetahui seberapa besar pengaruh bendung terhadap kecepatan aliran sungai

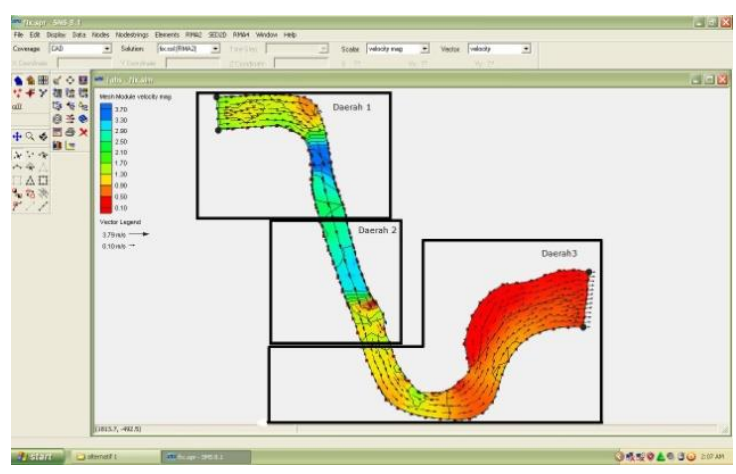

Gambar 6. profil setelah pemasangan Bendung.

Dari hasil running program penggunaan bendung mampu mengurangi terjadinya gerusan, namun hanya pada bagian tertentu saja sesuai gambar 5. pada bagian lain nya masih memiliki kecepatan aliran yg tinggi sehingga masih diperlukan alternatif lain penempatan bending Rekapitulasi hasil running programs di dapat nilai kecepatan yang menunjukan kecepatan aliran di titiktitik node tidak melebihi kecepatan kritis $\mathrm{D}_{50}$ yaitu sebesar $0,045 \mathrm{~m} / \mathrm{det}$.

Tabel 5. kecepatan aliran daerah rawan gerusan pada penempatan Bendung alternatif pertama

\begin{tabular}{l|lc}
\hline \multicolumn{3}{c}{$\begin{array}{c}\text { Daerah 1 } \\
\text { kecepatan }\end{array}$} \\
\hline $\mathrm{x}$ & $\mathrm{y}$ & \\
0.092 & -0.014 & \\
0.060 & -0.042 & \\
0.056 & -0.072 & \\
0.033 & -0.082 \\
\hline \multicolumn{3}{c}{ Daerah 2 } \\
\hline \multicolumn{3}{c}{ kecepatan } \\
\hline $\mathrm{x}$ & $\mathrm{y}$ \\
0.112 & -0.347 \\
0.064 & -0.232 \\
0.067 & -0.250 \\
0.110 & -0.299 \\
\hline
\end{tabular}


Daerah 3

kecepatan

\begin{tabular}{cc}
\hline $\mathrm{x}$ & $\mathrm{y}$ \\
0.024 & 0.033 \\
0.021 & 0.018 \\
0.036 & 0.013 \\
-0.032 & 0.201 \\
\hline
\end{tabular}

\section{Alternatif Kedua Penggunaan Bendung} konsolidasi

1) Alternatif kedua penempatan Bendung bertujuan untuk memberi pemecahan masalah, karena dirasa pada alternatif pertama tidak efektif untuk melindungi keseluruhan palung sungai

2) Data yang dimakasukkan dalam simulasi ini

3) Hasil dari running program akan di tabelkan

Hasil running programs adalah vektor kecepatan di daerah D1, D2 dapat di lihat pada gambar berikut.

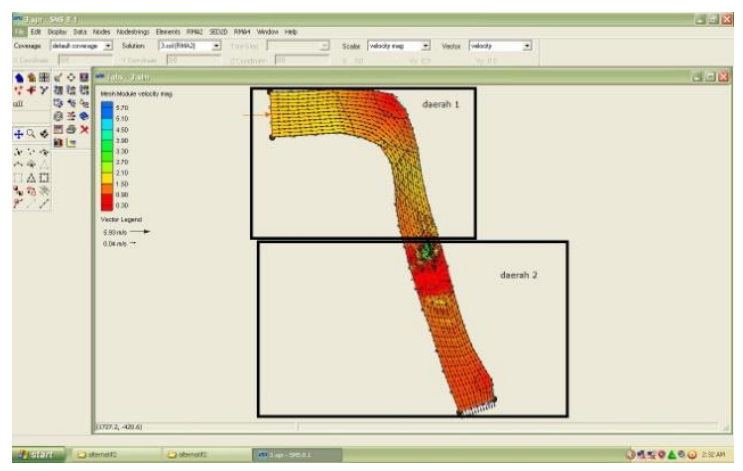

Gambar 7. profil Alternatif kedua penempatan Bendung

Dari hasil running programs di gambar 6. terjadi penurunan kecepatan aliran pada daerah yang sebelumnya masih memiliki kecepatan aliran yang melebihi kecepatan kritis.

Analisa hasil running programs gambar 7. penempatan bendung alternatif 2 menunjukan kecepatan aliran pada Daerah ( D1 ) yang terletak pada hulu sungai dan daerah ( D2 ) yang terletak pada hilir Sungai Brantas UMM Kampus III dapat dilihat di tabel 6.
Tabel 6. kecepatan aliran daerah Penempatan bendung alternatif kedua

\begin{tabular}{cc}
\hline \multicolumn{3}{c}{$\begin{array}{c}\text { Derah 1 } \\
\text { kecepatan }\end{array}$} \\
\hline $\mathrm{x}$ & $\mathrm{y}$ \\
\hline 0.043 & -0.025 \\
\hline 0.039 & -0.045 \\
\hline 0.044 & -0.052 \\
\hline 0.048 & -0.030 \\
\hline \multicolumn{3}{c}{ Daerah 2 } \\
\hline \multicolumn{3}{c}{ kecepatan } \\
\hline $\mathrm{x}$ & $\mathrm{y}$ \\
0.010 & 0.012 \\
0.008 & -0.012 \\
0.037 & -0.017 \\
0.017 & -0.045 \\
\hline
\end{tabular}

Dari hasil running programs di dapat nilai kecepatan di daerah dari tabel diatas menunjukan kecepatan aliran di titik-titik node tidak melebihi kecepatan kritis $\mathrm{D}_{50}$ yaitu sebesar $0,045 \mathrm{~m} /$ det.

\section{Penentuan Jumlah, Letak dan tinggi Bendung Yang Optimal}

Berdasarkan hasil simulasi yang dilakukan dengan menggunakan software surface water modelling system jumlah Bendung yang optimal adalah sebanyak 2 buah di letakkan pada potongan G-H dan Q-R.

\section{Tinggi Bendung pertama}

Asumsi $\mathrm{H}=4.8 \mathrm{~m}$

$$
\begin{aligned}
\mathrm{Be} & =\mathrm{B}-2(\mathrm{nkp}+\mathrm{Ka}) \times \mathrm{H} \\
& =15.2-2(0 \times 1+0.2) \times 4.8=13.28
\end{aligned}
$$

Control H

$\mathrm{Q} \quad=\mathrm{Cd} \times \mathrm{Be}^{\mathrm{x}} \mathrm{H}^{3 / 2}$

$190.594=1.3 \times 13.28 \times \mathrm{H}^{3 / 2}$

$$
\begin{aligned}
H & =\sqrt[3]{\left(\frac{190.594}{1.3 \times 13.18}\right)^{2}} \\
& =4.9 \text { meter }
\end{aligned}
$$

Tinggi bendung $=(528-521)-4.9=2.1 \mathrm{~m}$

Tinggi Bendung Kedua

Asumsi $\mathrm{H}=4.2 \mathrm{~m}$ 


$$
\begin{aligned}
\mathrm{Be} & =\mathrm{B}-2(\mathrm{nkp}+\mathrm{Ka}) \times \mathrm{H} \\
& =18.6-2(0.1+0.2) \times 4.2 \\
& =16.68
\end{aligned}
$$

Control $\mathrm{H}$

$\mathrm{Q}=\mathrm{Cd} \times \mathrm{Be}^{\mathrm{x}} \mathrm{H}^{3 / 2}$

$190.594=1.3 \times 16.68 \times \mathrm{H}^{3 / 2}$

$$
H=\sqrt[3]{\left(\frac{190.594}{1.3 \times 16.68}\right)^{2}}
$$$$
=4.2 \mathrm{~meter}
$$

Tinggi bendung $=(530-524)-4.2=1.8 \mathrm{~m}$

\section{KESIMPULAN DAN SARAN}

\section{Kesimpulan}

- Tingkat gerusan yang terjadi pada kondisis eksisting Sungai Brantas erutama di depan Kampus III UMM ukup besar terutama pada belokan sungai dari hasil running Programs SMS dengan debit banjir kala ualang 10 tahun di dapat nilai Maksimum $=0,25 \mathrm{~m} / \mathrm{det}$ dan Minimum $=$ $0,03 \mathrm{~m} / \mathrm{det}$ lebih besar dari kecepatan Kritis butiran $\mathrm{D}_{50}=0,045 \mathrm{~m} / \mathrm{det}$.

- Penggunaan Bendung efektif menurunkan knilai kecepatan aliran sebesar maksimum $=0.043 \mathrm{~m} /$ det dan Minimum $=0.01 \mathrm{~m} / \mathrm{det}$ dibawah nilai kecepatan Kritis $D_{50}=0,045 \mathrm{~m} /$ det. Sehingga dapat mengurangi resiko terjadinya longsor

- Tinggi bendung pertama $=2.1$ meter, Tinggi Bendung kedua $=1.8$ meter.

\section{Saran}

- Bendung yang dibangun harus memperhatikan bagian struktur pendukung lain untuk memperkuat Bendung yang dibuat.

\section{DAFTAR PUSTAKA}

Chow TeVen. (1985). Open Channel Hydraulics. Jakarta: Erlangga.

Departemen Pekerjaan Umum, Direktorat Jenderal Pengairan. (2002). Batuan, Sedimen, Agregat, bagian 2. Jakarta, Balitbang Kimpraswil.

Departemen Pekerjaan Umum, Direktorat Jenderal Pengairan. (2002). Bendung, Bendungan, Sungai, Irigasi, Pantai, bagian 8. Jakarta, Balitbang Kimpraswil.

Departemen Pekerjaan Umum, Direktorat Jenderal Pengairan. (2003).

Pengamanan Sungai, Modul-A 7.1 . Bandung, Balitbang Kimpraswil.

Departemen Pekerjaan Umum, Direktorat Jenderal Pengairan. (2002). Standar Perencanaan Irigasi. Kriteria Perencanaan Bangunan Utama (Kp02), cetakan 2. Jakarta, Balitbang Kimpraswil.

Enviromental Modeling Research Laboratory, (2003) USA

King dan Norton (1998) :A User's Guide To RMA2 Version 4.3 : USA.

Linsley, Ray K., danFranzini, Joseph B. (1991), Teknik Sumber Daya Air Jilid I : Diterjemahkan oleh Djoko Sasongko : Penerbit Erlangga.

Soejadi Bambang. (2003). Sedimen Transport, Modul Teknik Sipil dan Perencanaan, Institut Teknologi Sepuluh November, Surabaya.

Sosrodarsono Suyono, Ir. Tominaga, Masateru. (1985). Perbaikan dan Pengaturan Sungai.PT Pradnya Paramita. Jakarta.

Triatmojo, Bambang. (2012). Perencanaan Bangunan Pantai. Yogyakarta: Penerbit Beta Offset. 